\title{
The association of unwanted pregnancy and social support with depressive symptoms in pregnancy: evidence from rural Southwestern Ethiopia
}

Yohannes Dibaba ${ }^{*}$, Mesganaw Fantahun ${ }^{2}$ and Michelle J Hindin ${ }^{3}$

\begin{abstract}
Background: Depression in pregnancy has adverse health outcomes for mothers and children. The magnitude and risk factors of maternal depression during pregnancy is less known in developing countries. This study examines the association between pregnancy intention, social support and depressive symptoms in pregnancy in Ethiopia.

Methods: Data for this study comes from a baseline survey conducted as part of a community- based cohort study that involved 627 pregnant women from a Demographic Surveillance Site (DSS) in Southwestern Ethiopia. The Edinburgh Postnatal Depression Scale (EPDS) was used to measure depressive symptoms during pregnancy. Data on depressive symptoms, pregnancy intention, social support and other explanatory variables were gathered using an interviewer-administered structured questionnaire. The association between independent variables and depressive symptom during pregnancy was assessed using multivariable logistic regression.

Results: The prevalence of depressive symptoms during pregnancy was 19.9\% (95\% Cl, 16.8-23.1), using EPDS cut off point of 13 and above. The mean score on the EPDS was 8, ranging from 0 to 25 (SD \pm 5.4 ). Women reporting that the pregnancy was unwanted were almost twice as likely to experience depressive symptoms compared with women with a wanted pregnancy. (Adjusted Odds Ratio (AOR) $=1.96,95 \%$ Confidence Interval (Cl) 1.04-3.69) Women who reported moderate $(A O R=0.27 ; 95 \% \mathrm{Cl} 0.14-0.53)$ and high ( $\mathrm{AOR}=0.23,95 \% \mathrm{Cl} 0.11-0.47$ ) social support during pregnancy were significantly less likely to report depressive symptoms. Women who experienced household food insecurity and intimate partner physical violence during pregnancy were also more likely to report depressive symptoms.

Conclusion: About one in five pregnant women in the study area reported symptoms of depression. While unwanted pregnancy increases women's risk of depression, increased social support plays a buffering role from depression. Thus, identifying women's pregnancy intention and the extent of social support they receive during antenatal care visits is needed to provide appropriate counseling and improve women's mental health during pregnancy.
\end{abstract}

Keywords: Depressive symptoms, Social support, Pregnancy, Violence, Food insecurity, Ethiopia

\footnotetext{
* Correspondence: yohannes.dibaba@ju.edu.et

${ }^{1}$ Department of Population \& Family Health, College of Public Health and

Medical Sciences, Jimma University, Jimma, Ethiopia

Full list of author information is available at the end of the article
} 


\section{Background}

Mental health problems, such as depression, rank among the top causes of disability among women worldwide; however, they still remain inconspicuous as a component of reproductive health care [1]. Several studies have shown that depression, anxiety, and stress in pregnancy are risk factors for adverse outcomes for women and children. Depression places pregnant women at greater risk for inadequate prenatal care, increased alcohol use and poorer weight gain in pregnancy [1-3]. The adverse intergenerational effects of maternal depression on children's health, development, and behavior are also well documented [3-5]. For instance, a meta-analysis involving studies from both developed and developing countries showed that antenatal depression is associated with preterm birth, intrauterine growth restriction, and low birth weight [6]. A study from Ethiopia found that antenatal common mental disorders such as depression, anxiety and somatic symptoms are associated with prolonged labor, delayed initiation of breast feeding and more diarrheal episodes for infants [7]. Moreover, antenatal depression is a predictor of postnatal depression--women who are depressed during pregnancy have a higher risk of developing depression during the postpartum period $[8,9]$.

We focus on depressive symptomatology in pregnancy due to its adverse consequences for mothers and children. Unlike postnatal depression, which is increasingly recognized as an important public health issue in low-income countries, antenatal depression and its effects on maternal and child health is relatively less studied. Estimates of the prevalence of antenatal depression vary substantially. A recent systematic review of studies from developed countries found that antenatal depression affects 13\% of pregnant women in the second and $12 \%$ of women in third trimester [10]. Studies from South Asia and Latin America have reported rates of $20 \%$ and higher [11-14]. Evidence from developing countries suggests that depression during pregnancy is common-- in Sub-Saharan Africa prevalence ranged from $8.3 \%$ to $39 \%$ [15-18]. In Ethiopia, its magnitude and risk factors are not well known.

For most women, pregnancy is a time of positive expectation, but may also be a time for psychological and physiological challenges. It is accompanied by hormonal changes and can represent a time of increased vulnerability for the onset or return of depression [19]. However, the high prevalence of maternal depression in poor countries may be related to women's exposure to several depressionrelated risk factors, including poverty $[12,17,20]$, low social support [21-24], domestic violence [25-27], HIV/AIDS $[28,29]$ and reproductive health outcomes and behaviors such as high parity, unwanted pregnancy, unsafe abortion, infertility, and pregnancy complications [30-33].

The intersection of unintended pregnancy and maternal mental health is not well studied in developing countries.
The few studies that considered the influences of unintended pregnancy have shown that women with an unintended pregnancy are at an increased risk of depression during pregnancy than women with intended pregnancies [32-37]. Unintended pregnancy may increase a woman's exposure to psychosocial stressors, decrease social support provided to her by the partner, increase her level of depressive symptoms, and decrease her overall life satisfaction [34-36]. Some studies show no association between unintended pregnancy and depressive symptoms during pregnancy $[11,38]$.

Social support has the potential to play a protective role by buffering the impacts of life stress on emotional wellbeing of the woman during pregnancy $[24,39,40]$. Studies have shown that social support plays a buffering role from stressful life events by providing resources, support and strength during pregnancy. Understanding women's pregnancy intention and the extent of social support they receive may help to improve healthy behaviors during pregnancy and consequently better maternal and neonatal health outcomes. This study attempts to examine the associations between pregnancy intention, social support and depressive symptoms among pregnant women in Ethiopia, where there are high levels of unintended pregnancy (estimated at $32 \%$ in $2011^{\mathrm{a}}$ ) and women have low partner support during pregnancy [41].

\section{Methods}

\section{Study setting and sample}

The study took place in a Demographic Surveillance Site (DSS) in Gilgel Gibe Dam area in Southwestern Ethiopia. The Gilgel Gibe DSS is located at about $260 \mathrm{~km}$ southwest of Addis Ababa (the capital), and is used to collect vital events data through an update of multiple times in a year. The DSS area has a population of over 55,000 , a crude birth rate of 35 per 1000, and a population growth rate of about $2.7 \%$ per annum by $2012^{\mathrm{b}}$. Data collection at the site is done by Jimma University.

Data for the present study comes from a baseline survey conducted as part of a population-based cohort study in which pregnant women were identified and followed to examine factors that influence birth outcome. The outcome variable for the present analysis is maternal depression during pregnancy. All pregnant women in their $2^{\text {nd }}$ and $3^{\text {rd }}$ trimester living in the eleven kebeles ${ }^{\mathrm{c}}$ (Villages) in Gilgel Gibe DSS area were targeted for participation. Six hundred twenty seven pregnant women were identified from the DSS registration and from the records of Health Extension Workers who work in each village. A baseline survey was conducted from June to July 2012 on 627 pregnant women.

A structured questionnaire was developed and administered to all study participants (study tool attached as Additional file 1). The questionnaire was first developed in English and then translated and back translated to 
Oromo - a local language spoken in the study area. Ten trained female interviewers with a minimum of diplomalevel education collected the data. They had five days of training on how to administer the questionnaire, practice interviewing and role-plays, and how to deal with ethical issues. After the training, interviewers undertook a pilot study, and information from the pilot study was used to finalize the questionnaire. Data on depressive symptoms, pregnancy intention, social support and other explanatory variables were gathered using an interviewer-administered structured questionnaire. All study participants were interviewed at their home in private area. Ethical approval was obtained from the College of Health Sciences, Addis Ababa University. Moreover, support letters were obtained from regional, zonal and district health offices and kebele (village) administrations were informed about the study. Participants were asked for informed consent, and participation in the study was fully voluntary.

\section{Measurements}

Depressive symptoms were measured using the Edinburgh Postnatal Depression Scale (EPDS), which describes depression as cognitive and affective features that last for at least one week, including the inability to laugh, the inability to look forward to things with enjoyment, blaming oneself unnecessarily, anxiety or worry, being scared or panicky, the inability to cope, difficulty sleeping, feeling sad or miserable, crying, and thoughts of harming oneself [42]. The EPDS is widely used and has been validated for use during pregnancy in different countries and settings [43-47], including urban and rural Ethiopia [45,48]. A psychiatrist checked the translation and back translation of the depression questions. Moreover, considering the difficulty in understanding items 1 to 3 of the depression scale (EPDS), we used examples suggested and applied by Hanlon and colleagues in their validation study in Butajira (Central Ethiopia) [45]. The items were scored on a scale of $0-3$, allowing a total score ranging from 0 to 30 . The internal consistency of the EPDS was tested using Cronbach alpha and was found to be 0.85 . Like other previous studies that used EPDS cut of point of 13 and above [14,17], we used a cut of point of 13 and above on the scale to identify women with depressive symptoms. No other measures of mental health problems, such as anxiety and stress, were collected in this study.

The key independent variable was pregnancy intention. Women were asked to recall their feelings at the time they became pregnant: "At the time you became pregnant, did you want to become pregnant then, did you want to wait until later, or did you not want to have any (more) children at all?" The responses were categorized as (1) wanted then "wanted" (2) wanted to happen later "mistimed" and (3) did not want at all "unwanted".

Social support was measured using the Maternity Social Support Scale (MSSS) developed by Webster and colleagues
[49]. The scale contains six items and includes questions on family support, friendship network, help from spouse, conflict with spouse, feeling controlled by spouse, and feeling unloved by spouse. Each item was measured on a five-point Likert scale and a total score of 30 was possible. We classified social support in to three categories; high social support (for scores 24-30), medium social support (18-23) and low social support (below 18) categories. The internal consistency of the scale was tested using Cronbach's alpha and was found to be 0.74 .

We also considered several other explanatory variables based on previous studies including age (coded as 15-24, 25-34 and 35-49 years), women's education (none, primary and secondary and above), occupation (housewife, farmer and employed in other services), wealth index, parity, history of miscarriage or stillbirth, perceived work burden during pregnancy, intimate partner violence, and household food security. The wealth index was computed from ownership of the following household assets: radio, television, electricity, toilet, farm land, and animals such as cattle, sheep, and goats. Principal Component Analysis (PCA) was conducted and the resulting index was divided into three categories representing poor, middle and wealthy.

Women were asked whether they have experienced a miscarriage or stillbirth in their lifetime to measure any experience of pregnancy loss. All women participating in the study were asked about the type of physical work they did in the seven days before the survey, and whether they perceived that the work was 'difficult,' 'moderate' or 'easy' for them. Intimate partner violence was measured by asking women whether they have ever been beaten during the current pregnancy by their husbands or partners.

Household food insecurity was measured with a six-item scale based on previously validated measures in developing countries. Women were asked whether because food ran out or money was not enough to buy food, in the last 3 months, they: (1) worried about running out of food, (2) ran out of food, (3) reduced the variety of food for their children, (4) did not have enough food to give their children to eat, (5) spent the whole day without food, and (6) or anyone else in the household had ever had to ask others for food or money to buy food. For each item, 'yes' was coded with " 1 " and no coded as " 0 " and a summative index of food insecurity was created. Households were classified as 'food-insecure' if the respondent answered affirmatively to two or more of the six household food security questions. The scale had an internal consistency (Cronback's alpha) of 0.85 .

\section{Data analysis}

Data were analyzed using STATA Version 11. First, frequency distributions of the characteristics of study population were tabulated. Next, bivariate analysis was done to compare depressive symptoms by study characteristics 
using Chi-square tests. Variables were entered into multivariate models based on their association in the bivariate analysis (at $\mathrm{P}<0.20)$ including almost all variables that were expected to be associated from the literature review. Multivariable logistic regression was done to identify factors that are independently and significantly associated with depression during pregnancy. Odds ratios and 95\% confidence intervals are reported.

\section{Results}

Of the 627 women targeted for inclusion in the study, 622 were successfully interviewed (99\% response rate). The mean age of study participants was 26 years, and ranged from 14 to 40 years (SD \pm 5.02$)$. Nearly all $(99 \%)$ of the respondents were married, $72 \%$ had no formal education, $77 \%$ were housewives, and $76 \%$ lived in rural areas. The median gestational age of the participants was 7 months. The average number of children ever born was 3.9 , and nearly one-third (32.6\%) had given birth to 5 or more children. With regards to pregnancy intention, $59 \%$ of women reported that their current pregnancy was wanted, while $28 \%$ and $13 \%$ of women their current pregnancy was mistimed and unwanted respectively. Forty-one percent of women reported food insecurity during pregnancy (Table 1).

The overall prevalence of depressive symptoms among the pregnant women was $19.9 \%$ (95\% CI, 16.8-23.1). The mean score on the EPDS was 8, and ranged from 0 to 25 (SD \pm 5.4 ). Bivariate analysis showed that the prevalence of depression during pregnancy did not vary by age, wealth index, parity and trimester of pregnancy. However, the prevalence of prenatal depression varied by education, occupation, pregnancy intention, social support, perceived work burden, intimate partner physical violence, food security status and previous experience of miscarriage or stillbirth. Considering educational status, a relatively higher proportion of women with secondary and above level of education (24\%) reported depression than women with no education (22\%) or with primary education (11.6\%). The prevalence of depressed mood in pregnancy also varied by pregnancy intention--35\% of women with an unwanted pregnancy reported depressive symptoms as compared to $16 \%$ of women with wanted pregnancy. Moreover, women who scored 13 and above on the EPDS scale were more likely to have low social support, high work burden, and be farmers by occupation. Women with a high score on the EDPS were also more likely to have experienced intimate partner violence, food insecurity, and have previous history of miscarriage or stillbirth. Social support was inversely related to depressive symptoms with women reporting high social support being less likely to have depressive symptoms (Table 2).

Women who did not want the current pregnancy were nearly twice as likely as women who wanted the pregnancy
Table 1 Description of study participants, Southwestern Ethiopia, 2012

\begin{tabular}{|c|c|c|}
\hline Variables & Number & Percent \\
\hline \multicolumn{3}{|l|}{ Age } \\
\hline $15-24$ & 207 & 33.3 \\
\hline $25-34$ & 360 & 57.9 \\
\hline $35+$ & 55 & 8.8 \\
\hline \multicolumn{3}{|l|}{ Educational status } \\
\hline No formal education & 447 & 71.9 \\
\hline Primary & 146 & 23.5 \\
\hline Secondary \& above & 29 & 4.7 \\
\hline \multicolumn{3}{|l|}{ Residence } \\
\hline Rural & 475 & 76.4 \\
\hline Urban & 147 & 23.6 \\
\hline \multicolumn{3}{|l|}{ Marital status } \\
\hline Currently married & 618 & 99.4 \\
\hline Widowed or divorced & 4 & 0.6 \\
\hline \multicolumn{3}{|l|}{ Occupation } \\
\hline House wife & 484 & 77.8 \\
\hline Farmer & 92 & 14.8 \\
\hline Employed/family business & 46 & 7.4 \\
\hline \multicolumn{3}{|l|}{ Trimester of pregnancy } \\
\hline Second & 231 & 37.1 \\
\hline Third & 391 & 62.9 \\
\hline \multicolumn{3}{|l|}{ Household food security status } \\
\hline Food Secure & 365 & 58.7 \\
\hline Food insecure & 257 & 41.3 \\
\hline \multicolumn{3}{|l|}{ Pregnancy Intention } \\
\hline Wanted & 367 & 59.0 \\
\hline Mistimed & 175 & 28.1 \\
\hline Unwanted & 80 & 12.9 \\
\hline \multicolumn{3}{|l|}{ Parity } \\
\hline 0 & 84 & 13.5 \\
\hline $1-2$ & 163 & 26.2 \\
\hline $3-4$ & 172 & 27.6 \\
\hline $5^{+}$ & 203 & 32.7 \\
\hline Total & 622 & 100 \\
\hline
\end{tabular}

to experience depression during pregnancy (Odds Ratio $(\mathrm{OR})=1.96,95 \%$ CI: 1.04-3.69). Women who reported a mistimed pregnancy did not differ significantly from those who wanted the pregnancy in prenatal depression. The level of social support was strongly associated with depression during pregnancy. Women with high social support were significantly less likely to experience depression during pregnancy compared with women who had high levels of social support (OR: 0.23, 95\% CI 0.11-0.47). Those with moderate score on the social support scale were also less 
Table 2 Prevalence of maternal depressive symptoms by women's pregnancy intentions, social support and other characteristics, Southwestern Ethiopia, 2012

\begin{tabular}{|c|c|c|c|c|}
\hline \multirow[t]{2}{*}{ Variables } & \multicolumn{2}{|c|}{$\begin{array}{l}\text { Depressive } \\
\text { symptoms } \\
\text { (EPDS } \geq 13 \text { ) }\end{array}$} & \multirow[t]{2}{*}{$\begin{array}{l}\% \text { with } \\
\text { depressive } \\
\text { symptoms }\end{array}$} & \multirow[t]{2}{*}{$\mathbf{P}$} \\
\hline & No & Yes & & \\
\hline \multicolumn{5}{|l|}{ Pregnancy Intention } \\
\hline Wanted & 307 & 60 & 16.4 & \multirow[t]{3}{*}{0.001} \\
\hline Mistimed & 139 & 36 & 20.6 & \\
\hline Unwanted & 52 & 28 & 35.0 & \\
\hline \multicolumn{5}{|l|}{ Social support } \\
\hline Low & 30 & 36 & 53.0 & \multirow[t]{3}{*}{0.001} \\
\hline Medium & 253 & 53 & 22.6 & \\
\hline High & 215 & 35 & 16.8 & \\
\hline \multicolumn{5}{|l|}{ Age } \\
\hline $15-24$ & 171 & 36 & 17.4 & \multirow[t]{3}{*}{0.53} \\
\hline $25-34$ & 284 & 76 & 21.1 & \\
\hline $35+$ & 43 & 12 & 21.8 & \\
\hline \multicolumn{5}{|l|}{ Educational status } \\
\hline No formal education & 347 & 100 & 34.7 & \multirow[t]{3}{*}{0.02} \\
\hline Primary & 129 & 17 & 11.6 & \\
\hline Secondary \& above & 22 & 7 & 24.1 & \\
\hline \multicolumn{5}{|l|}{ Occupation } \\
\hline Housewife & 411 & 71 & 14.7 & \multirow[t]{3}{*}{0.001} \\
\hline Farmer & 51 & 40 & 44.0 & \\
\hline Employed/family business & 36 & 13 & 26.5 & \\
\hline \multicolumn{5}{|l|}{ Wealth tertile } \\
\hline Poor & 165 & 43 & 20.7 & \multirow[t]{3}{*}{0.17} \\
\hline Middle & 159 & 48 & 23.2 & \\
\hline Rich & 174 & 33 & 15.9 & \\
\hline \multicolumn{5}{|l|}{ Parity } \\
\hline 0 & 70 & 15 & 17.9 & \multirow[t]{4}{*}{0.69} \\
\hline $1-2$ & 134 & 29 & 17.8 & \\
\hline $3-4$ & 140 & 31 & 18.0 & \\
\hline $5^{+}$ & 154 & 49 & 24.1 & \\
\hline \multicolumn{5}{|l|}{ Trimester of pregnancy } \\
\hline $2^{\text {nd }}$ & 186 & 45 & 19.5 & \multirow[t]{2}{*}{0.83} \\
\hline $3^{\text {rd }}$ & 312 & 79 & 20.2 & \\
\hline \multicolumn{5}{|l|}{ History of miscarriage/stillbirth } \\
\hline No & 462 & 103 & 18.2 & \multirow[t]{2}{*}{0.001} \\
\hline Yes & 36 & 21 & 36.8 & \\
\hline \multicolumn{5}{|l|}{ Presence of domestic violence } \\
\hline No & 484 & 112 & 18.8 & \multirow[t]{2}{*}{0.001} \\
\hline Yes & 14 & 12 & 46.2 & \\
\hline \multicolumn{5}{|l|}{ Household food security } \\
\hline Food Secure & 336 & 29 & 8.0 & 0.001 \\
\hline Food insecure & 162 & 95 & 37.0 & \\
\hline
\end{tabular}

Table 2 Prevalence of maternal depressive symptoms by women's pregnancy intentions, social support and other characteristics, Southwestern Ethiopia, 2012 (Continued)

\begin{tabular}{lllll}
\hline Perceived work burden & & & & \\
\hline Difficult & 109 & 43 & 28.3 & 0.01 \\
\hline Moderate & 185 & 41 & 18.1 & \\
\hline Easy & 204 & 40 & 16.4 \\
\hline Total & 498 & 124 & 19.9 \\
\hline
\end{tabular}

likely (OR: 0.27, 95\% CI 0.14-0.53) to experience depression during pregnancy. With regards to occupation, women engaged in farming (OR: 3.43, 95\% CI 1.95-6.05), and those engaged in the service sector such as family business or government employee (OR: 2.50, 95\% CI 1.13-5.56) were more likely to report depressive symptoms in pregnancy than house wives. Moreover, women with household food insecurity are nearly five times as likely to be depressed during pregnancy as compared to women from food secure households (OR: 4.60, 95\% CI 2.75-7.70). Presence of intimate partner violence during pregnancy was also associated with an increased likelihood that a woman was depressed during pregnancy, although the association was marginally significant (Table 3).

\section{Discussion}

The magnitude of antenatal depression in the current study population, $19.9 \%$ (95\% CI, 16.8-23.1), though within the range of findings reported from Sub-Saharan Africa and other developing countries [11-17], is high when compared to findings from a systematic review that showed prevalence of prenatal depression of $12.0 \%$ in developed countries [10]. In Sub-Saharan Africa, the prevalence of antenatal depression ranged from $8.3 \%$ to $39 \%$ [16-18]. A very high level of depression was reported in a recent study in Cape Town, South Africa, where depressed mood in pregnancy was $39 \%$. There has been no study of antenatal depression in Ethiopia, but in one study that used the Hopkins symptoms checklist (HSCL) to measure the prevalence of postnatal maternal and paternal symptoms of anxiety and depression, the prevalence of depression (defined as mean score for each HSCL item of $\geq 1.75$ ) among adult women was $37 \%$ [20].

In this study, factors that were significantly associated with depressed mood in pregnancy include pregnancy intention, social support, occupation, food security status and partner violence during pregnancy. With regards to pregnancy intention, having unwanted pregnancy, not mistimed pregnancy, is associated with antenatal depression. Women reporting unwanted pregnancy are nearly 2 times more likely to be depressed as compared to women with planned pregnancies. Several previous studies have shown such an association between unwanted pregnancy and depression during pregnancy 
Table 3 Unadjusted and adjusted odds ratios of women's experience of maternal depressive symptoms by pregnancy intention, social support and other characteristics, Southwestern Ethiopia, 2012

\begin{tabular}{|c|c|c|}
\hline \multirow[t]{2}{*}{ Variables } & \multicolumn{2}{|c|}{ Depressed mood, OR (95\% Cl) } \\
\hline & $\begin{array}{l}\text { Unadjusted OR } \\
(95 \% \mathrm{Cl})\end{array}$ & $\begin{array}{l}\text { Adjusted }{ }^{1} \text { OR } \\
(95 \% \mathrm{Cl})\end{array}$ \\
\hline \multicolumn{3}{|l|}{ Pregnancy intention } \\
\hline Wanted (reference) & 1.00 & 1.00 \\
\hline Mistimed & $1.33(0.84-2.10)$ & $0.97(0.56-1.66)$ \\
\hline Unwanted & $2.76(1.61-4.70)^{* * *}$ & $1.96(1.04-3.69)^{*}$ \\
\hline \multicolumn{3}{|l|}{ Social support } \\
\hline Low (reference) & 1.00 & 1.00 \\
\hline Medium & $0.17(0.10-.31)^{* * *}$ & $0.27(0.14-0.53)^{* * *}$ \\
\hline High & $0.14(0.07-.25)^{* * *}$ & $0.23(0.11-0.47)^{* * *}$ \\
\hline \multicolumn{3}{|l|}{ Educational status } \\
\hline No education (reference) & 1.00 & 1.00 \\
\hline Primary & $0.46(0.26-.79)^{*}$ & $0.56(0.30-1.05)$ \\
\hline Secondary \& above & $1.10(0.46-2.66)$ & $1.83(0.64-5.27)$ \\
\hline \multicolumn{3}{|l|}{ Wealth tertile } \\
\hline Lower (reference) & 1.00 & 1.00 \\
\hline Middle & $1.16(0.73-1.85)$ & $1.43(0.82-2.51)$ \\
\hline Upper & $0.73(0.44-1.20)$ & $0.88(0.48-1.62)$ \\
\hline \multicolumn{3}{|l|}{ Occupation } \\
\hline Housewife (reference) & 1.00 & 1.00 \\
\hline Farmer & $4.54(2.80-7.37)^{* *}$ & $3.43(1.95-6.05)^{* *}$ \\
\hline Employed/family business & $2.09(1.06-4.14)^{*}$ & $2.50(1.13-5.56)^{*}$ \\
\hline \multicolumn{3}{|l|}{$\begin{array}{l}\text { Perceived work burden } \\
\text { in pregnancy }\end{array}$} \\
\hline Too difficult (reference) & 1.00 & 1.00 \\
\hline Moderate & $0.56(0.34-.92)^{*}$ & $0.72(0.41-1.26)$ \\
\hline Easy & $0.49(0.30-.81)^{* *}$ & $0.68(0.38-1.19)$ \\
\hline Food insecurity & $6.79(4.31-10.72)^{* * *}$ & $4.60(2.75-7.70)^{* * *}$ \\
\hline History of miscarriage or stillbirth & $2.62(1.47-4.67)^{* *}$ & $1.27(0.62-2.57)$ \\
\hline $\begin{array}{l}\text { Partner violence } \\
\text { during pregnancy }\end{array}$ & $3.75(1.42-8.92)^{* *}$ & $3.41(1.18-9.10)^{* *}$ \\
\hline
\end{tabular}

${ }^{1}$ Adjusted for education, wealth tertile, occupation, perceived work burden, food security status, history of miscarriage or still birth and partner physical violence during pregnancy.

${ }^{*} p<0.05 * * p<0.01,{ }^{* * *} p<0.001$

[32,34,35]. However, women reporting mistimed pregnancies did not differ significantly from women with wanted pregnancy in terms of depressive symptoms during pregnancy.

The strongest association in this study was with social support. In this study, women with high social support were 0.26 times as likely as women with low social support to experience antenatal depression. Similarly, women with moderate social support were 0.27 times as likely as women with low social support to experience antenatal depression. The association between social support and depression during pregnancy has been confirmed by studies from both developing and developed countries. These studies have shown that social support plays a buffering role from stressful life events by providing resources, support and strength during pregnancy $[21,39]$. Much related to the absence of social support is the presence of intimate partner violence during pregnancy. In this study, although very few women (about 4\%) reported ever been beaten during the current pregnancy, there was a significant association between intimate partner violence and depression during pregnancy, as has been found in several previous studies [26,27].

Household level food insecurity is another important associated factor with depressed mood in pregnancy. About $41 \%$ of women in this study reported food insecurity, which can be one main cause of stress in life. Consequently, women reporting food insecurity are nearly five times as likely as food secure women to report depressive symptoms during pregnancy. Food insecurity is a major problem in Ethiopia and the study area in particular [20]. Moreover, this study took place in the summer months of June and July and in rural Ethiopia, these are times when most households run out of food, and food insecurity tends to be high during this season. Studies have also indicated that the effects of food insecurity extend beyond the nutritional effects and include anxiety and depression [20].

Our result indicates that socio-demographic factors such as age, parity, place of residence and wealth were not associated with prenatal depression. Similarly, the association between education and depressive symptoms was attenuated once the effects of other socio-demographic and obstetric factors were controlled for. Although such factors were found to be associated in some previous studies $[17,25]$, a systematic review proved that such factors (age, parity, socio-economic status, and education) were not significant in multivariate models in majority of the studies included in the review [34].

\section{Limitations of the study}

Despite the contributions that it makes to the literature on antenatal depression, this study has some limitations. First, although it examines the influences of unwanted pregnancy and social support on depressive symptoms during pregnancy, the study has not considered the presence of other important mental health conditions such as anxiety and stress in pregnancy. Second, given the nature of the study, a cross-sectional study, it is not possible to establish causal relationships. There is also a possibility of recall bias when reporting pregnancy intention. Moreover, standard instrument was not used to measure the variable 'partner physical violence' during pregnancy.

\section{Conclusion}

Overall, our study found a high level of depressive symptoms among pregnant women in the study area. Although the study lacks clinical validation, the EPDS 
has been validated in several settings among pregnant women and is found to be a valid screening instrument for depressive symptoms during pregnancy. As shown above, much of these stressful life experiences may stem from the socio-economic context in which women live such as food insecurity, intimate partner violence and unwanted pregnancy. Understanding the factors that buffer the effects of stressful life events on depression in pregnancy is important. This study demonstrated that social support during pregnancy plays such a buffering role against depression. It is therefore important to screen for depression during pregnancy and provide appropriate counseling during routine prenatal care visits. The WHO has made such recommendations, integration of mental health into primary health care settings in developing countries [50]). In conclusion, enabling women to meet their reproductive goals and interventions that encourage social support in pregnancy help a lot in reducing mental health problems such as depression.

\section{Endnotes}

a Analysis of 2011 EDHS data for pregnant women showed that $32 \%$ of pregnancies were not intended. But, for births in the five years before the survey, $25 \%$ of them were reported as unintended.

${ }^{\mathrm{b}}$ Data from DSS registration for the year 2012.

${ }^{\mathrm{c}}$ Kebele is the smallest administrative unit in Ethiopia.

\section{Additional file}

Additional file 1: Questionnaire for baseline survey among pregnant women in Gilgel Gibe HDSS area, SW Ethiopia.

\section{Abbreviations}

CSA: Central Statistical Authority; DSS: Demographic Surveillance Site; EPDS: Edinburgh Postnatal Depression Scale; OR: Odds Ratio; WHO: World Health Organization.

\section{Competing interests}

We declare that we have no any competing interests.

\section{Authors' contributions}

YD designed the study, monitored the data collection, analyzed the data, and wrote the first draft of the manuscript. MF and MJH participated in the design of the study, supervised the whole process and reviewed and modified the drafts of the manuscript. All authors revised and approved the final version of this manuscript.

\section{Acknowledgments}

We are very grateful to the study participants for providing information, and the data collectors and supervisors for collecting the data. The study was funded by the African Doctoral Dissertation Research Fellowship Program (ADDRF) and Addis Ababa University through thematic research project.

\section{Author details}

${ }^{1}$ Department of Population \& Family Health, College of Public Health and Medical Sciences, Jimma University, Jimma, Ethiopia. ${ }^{2}$ School of Public Health, College of Health Sciences, Addis Ababa University, Addis Ababa, Ethiopia. ${ }^{3}$ Johns Hopkins Bloomberg School of Public Health, Johns Hopkins University, Baltimore, MD, USA.
Received: 18 December 2012 Accepted: 19 June 2013

Published: 24 June 2013

\section{References}

1. WHO: Mental health aspects of women's reproductive health; A global review of the litreature. 2009: http://www.who.int/reproductivehealth/publications/ general/9789241563567/en/index.html, accessed on 16/08/2012.

2. Wachs TD, Black M, Engle P: Maternal depression: a global threat to children's health, development, and behavior and to human rights. Child Development Perspectives 2009, 3:51-59.

3. Dunkel Schetter C, Tanner L: Anxiety, depression and stress in pregnancy: implications for mothers, children, research, and practice. Curr Opin Psychiatry 2012, 25(2):141-148.

4. Kinsella MT, Monk C: Impact of maternal stress, depression and anxiety on fetal neurobehavioral development. Clin Obstet Gynecol 2009, 52(3):425-440.

5. Cox AD: Maternal depression and impact on children's development. Arch Dis Child 1988, 63(1):90-95.

6. Grote NK, Bridge JA, Gavin AR, Melville JL, lyengar S, Katon WJ: A meta-analysis of depression during pregnancy and the risk of preterm birth, low birth weight and intrauterine growth restriction. Arch Gen Psychiatry 2010, 67(10):1012-1024.

7. Hanlon C, Medhin G, Alem A, Tesfaye F, Lakew Z, Worku B, et al: Impact of antenatal common mental disorders upon perinatal outcomes in Ethiopia: the P-MaMiE population-based cohort study. Trop Med Int Health 2009, 14(2):156-166.

8. Wissart J, Parshad O, Kulkarni S: Prevalence of pre- and postpartum depression in Jamaican women. BMC Pregnancy Childbirth 2005, 5:15

9. Heron J, O'Connor TG, Evans J, Golding J, Glover V: The course of anxiety and depression through pregnancy and the postpartum in a community sample. J Affect Disord 2004, 80(1):65-73.

10. Bennett HA, Einarson A, Taddio A, Koren G, Einarson TR: Prevalence of depression during pregnancy: systematic review. Obstet Gynecol 2004, 103(4):698-709.

11. Faisal-Cury A, Menezes $P$, Araya R, Zugaib M: Common mental disorders during pregnancy: prevalence and associated factors among low-income women in Sao Paulo, Brazil: depression and anxiety during pregnancy. Arch Womens Ment Health 2009, 12(5):335-343.

12. Husain N, Cruickshank K, Husain M, Khan S, Tomenson B, Rahman A: Social stress and depression during pregnancy and in the postnatal period in British Pakistani mothers: a cohort study. J Affect Disord 2012, 140(3):268-276.

13. Husain N, Parveen A, Husain M, Saeed Q, Jafri F, Rahman R, et al: Prevalence and psychosocial correlates of perinatal depression: a cohort study from urban Pakistan. Arch Womens Ment Health 2011, 14(5):395-403.

14. Golbasi Z, Kelleci M, Kisacik G, Cetin A: Prevalence and correlates of depression in pregnancy among Turkish women. Matern Child Health J 2010, 14(4):485-491.

15. Cox JL: Psychiatric morbidity and pregnancy: a controlled study of 263 semi-rural Ugandan women. Br J Psychiatry 1979, 134:401-405.

16. Abiodun OA, Adetoro OO, Ogunbode OO: Psychiatric morbidity in a pregnant population in Nigeria. Gen Hosp Psychiatry 1993, 15(2):125-128.

17. Hartley M, Tomlinson M, Greco E, Comulada WS, Stewart J, le Roux I, et al: Depressed mood in pregnancy: prevalence and correlates in two Cape Town peri-urban settlements. Reprod Health 2011, 8:9.

18. Adewuya AO, Ola BA, Aloba OO, Dada AO, Fasoto OO: Prevalence and correlates of depression in late pregnancy among Nigerian women. Depress Anxiety 2007, 24(1):15-21.

19. Smith MV, Shao L, Howell H, Lin H, Yonkers KA: Perinatal depression and birth outcomes in a Healthy Start project. Matern Child Health J 2011, 15(3):401-409.

20. Hadley C, Tegegn A, Tessema F, Cowan JA, Asefa M, Galea S: Food insecurity, stressful life events and symptoms of anxiety and depression in east Africa: evidence from the Gilgel Gibe growth and development study. J Epidemiol Community Health 2008, 62(11):980-986.

21. Collins NL, Dunkel-Schetter C, Lobel M, Scrimshaw SC: Social support in pregnancy: psychosocial correlates of birth outcomes and postpartum depression. J Pers Soc Psychol 1993, 65(6):1243-1258.

22. Divney AA, Sipsma H, Gordon D, Niccolai L, Magriples U, Kershaw T: Depression during pregnancy among young couples: the effect of personal and partner experiences of stressors and the buffering effects of social relationships. J Pediatr Adolesc Gynecol 2012, 25(3):201-207.

23. Spoozak L, Gotman N, Smith MV, Belanger K, Yonkers KA: Evaluation of a social support measure that may indicate risk of depression during pregnancy. J Affect Disord 2009, 114(1-3):216-223. 
24. Norbeck JS, Anderson NJ: Life stress, social support, and anxiety in mid- and late-pregnancy among low income women. Res Nurs Health 1989, 12(5):281-287.

25. Ali FA, Israr SM, Ali BS, Janjua NZ: Association of various reproductive rights, domestic violence and marital rape with depression among Pakistani women. BMC Psychiatry 2009, 9:77.

26. Zhang Y, Zou S, Cao Y: Relationship between domestic violence and postnatal depression among pregnant Chinese women. Int J Gynaecol Obstet 2012, 116(1):26-30.

27. Ludermir AB, Lewis G, Valongueiro SA, de Araujo TV, Araya R: Violence against women by their intimate partner during pregnancy and postnata depression: a prospective cohort study. Lancet 2010, 376(9744):903-910.

28. Stein A, Krebs G, Richter L, Tomkins A, Rochat T, Bennish ML: Babies of a pandemic. Arch Dis Child 2005, 90(2):116-118.

29. Dhanda A, Narayan T: Mental health and human rights. Lancet 2007, 370(9594):1197-1198.

30. Rees DI, Sabia JJ: The relationship between abortion and depression: new evidence from the fragile families and child wellbeing study. Med Sci Monit 2007, 13(10):CR430-CR436.

31. Pedersen W: Abortion and depression: a population-based longitudinal study of young women. Scand J Public Health 2008, 36(4):424-428.

32. Christensen AL, Stuart EA, Perry DF, Le HN: Unintended pregnancy and perinatal depression trajectories in low-income, high-risk Hispanic immigrants. Prevention science 2011, 12(3):289-299.

33. Berenson $A B$, Breitkopf $C R, W u$ ZH: Reproductive correlates of depressive symptoms among low- income minority women. Obstet Gynecol 2003, 102(6):1310-1317

34. Lancaster CA, Gold KJ, Flynn HA, Yoo H, Marcus SM, Davis MM: Risk factors for depressive symptoms during pregnancy: a systematic review. Am J Obstet Gynecol 2010, 202(1):5-14.

35. Orr ST, Miller CA: Unintended pregnancy and the psychosocial well-being of pregnant women. Womens Health Issues 1997, 7(1):38-46.

36. Gipson JD, Koenig MA, Hindin MJ: The effects of unintended pregnancy on infant, child, and parental health: a review of the literature. Stud Fam Plann 2008, 39(1):18-38.

37. Hardee K, Eggleston E, Wong EL, Irwanto, Hull TH: Unintended pregnancy and women's psychological well-being in Indonesia. J Biosoc Sci 2004, 36(5):617-626

38. Phipps MG, Nunes AP: Assessing pregnancy intention and associated risks in pregnant adolescents. Matern Child Health J 2012, 16(9):1820-1827.

39. Elsenbruch S, Benson S, Rucke M, Rose M, Dudenhausen J, Pincus-Knackstedt MK, et al: Social support during pregnancy: effects on maternal depressive symptoms, smoking and pregnancy outcome. Hum Reprod 2007, 22(3):869-877.

40. Mercer RT, Ferketich SL: Stress and social support as predictors of anxiety and depression during pregnancy. ANS Adv Nurs Sci 1988, 10(2):26-39.

41. Geleto A, Aseffa F, Dessie Y: Do male involve in Antenatal care? The views of women attending ANC in Harari Public Health Institutions, Eastern Ethiopia. Harar Bulletin of Health Sciences 2012, 6:76-92.

42. Cox JL, Holden JM, Sagovsky R: Detection of postnatal depression. Development of the 10-item Edinburgh Postnatal Depression Scale. Br J Psychiatry 1987, 150:782-786.

43. Lau Y, Wang Y, Yin L, Chan KS, Guo X: Validation of the Mainland Chinese version of the Edinburgh postnatal depression scale in Chengdu mothers. Int J Nurs Stud 2010, 47(9):1139-1151.

44. Rubertsson C, Borjesson K, Berglund A, Josefsson A, Sydsjo G: The Swedish validation of Edinburgh Postnatal Depression Scale (EPDS). Nord J Psychiatry 2011, 65(6):414-418

45. Hanlon C, Medhin G, Alem A, Araya M, Abdulahi A, Hughes M, et al: Detecting perinatal common mental disorders in Ethiopia: validation of the self-reporting questionnaire and Edinburgh Postnatal Depression Scale. J Affect Disord 2008, 108(3):251-262.

46. Bergink V, Kooistra L, Lambregtse-van den Berg MP, Wijnen $H$, Bunevicius $R$, van Baar A, et al: Validation of the Edinburgh Depression Scale during pregnancy. J Psychosom Res 2011, 70(4):385-389.

47. Adewuya AO, Ola BA, Dada AO, Fasoto OO: Validation of the Edinburgh Postnatal Depression Scale as a screening tool for depression in late pregnancy among Nigerian women. J Psychosom Obstet Gynaecol 2006, 27(4):267-272.

48. Tesfaye M, Hanlon C, Wondimagegn D, Alem A: Detecting postnatal common mental disorders in Addis Ababa, Ethiopia: validation of the
Edinburgh Postnatal Depression Scale and Kessler Scales. J Affect Disord 2010, 122(1-2):102-108.

49. Webster J, Linnane JW, Dibley LM, Hinson JK, Starrenburg SE, Roberts JA: Measuring social support in pregnancy: can it be simple and meaningful? Birth 2000, 27(2):97-101.

50. WHO: Maternal mental health and child health and development in low and middle income countries: report of the meeting held in Geneva, 30 January - 1 February, 2008. World Health Organization; 2008. http://www.who.int/ mental_health/prevention/suicide/mmh_jan08_meeting_report.pdf.

doi:10.1186/1471-2393-13-135

Cite this article as: Dibaba et al:: The association of unwanted pregnancy and social support with depressive symptoms in pregnancy: evidence from rural Southwestern Ethiopia. BMC Pregnancy and Childbirth 2013 13:135.

\section{Submit your next manuscript to BioMed Central and take full advantage of:}

- Convenient online submission

- Thorough peer review

- No space constraints or color figure charges

- Immediate publication on acceptance

- Inclusion in PubMed, CAS, Scopus and Google Scholar

- Research which is freely available for redistribution 